\title{
The Importance of the use of Clothes with Solar UV Protection
}

\author{
Rubén D Piacentini ${ }^{1 *}$, Erika Pierobon², Ariel R Piacentini², and Graciela M Salum ${ }^{3}$ \\ ${ }^{1}$ Laboratorio de Eficiencia Energética, Sustentabilidad y Cambio Climático, IMAE, Facultad de Ciencias Exactas, Ingeniería y Agrimensura, Universidad \\ Nacional de Rosario, Argentina
}

${ }^{2}$ Ocean 5, 2000 Rosario, Argentina

${ }^{3}$ Biological Sciences and Engineering School, Yachay Tech University, Hacienda San José, Urcuquí, Ecuador

Submission: May 02, 2018; Published: May 15, 2018

*Corresponding author: Rubén D Piacentini, Laboratorio de Eficiencia Energética, Sustentabilidad y Cambio Climático, IMAE, Facultad de Ciencias Exactas, Ingeniería y Agrimensura, Universidad Nacional de Rosario, Beruti y Riobamba, 2000, Rosario, Argentina

Email: ruben.piacentini@gmail.com

\begin{abstract}
Normal clothes protect human body form the harmful effects of intense solar Ultraviolet (UV) radiation in a wide range of values of the UV Protection Factor (indicated as UPF). In the present review, we describe how this factor is defined, how it is related to the well-known Solar Protection Factor (SPF) of sunscreens and what kind of fabric characteristics and materials determine the protection level. We also present a typical measurement of solar transmittance, solar protection and the UPF value determined in actual conditions of fabrics exposed to solar radiation. We propose that all fabrics need to include universally the identification of its UPF.

Keywords: Solar UV Protection; Ultraviolet; Sunscreens; Solar transmittance; Solar protection; Solar radiation; Sun burning; Skin cancer; Fabric; Clothes

Abbreviation: UV: Ultraviolet; UPF: UV Protection Factor; SPF: Solar Protection Factor; ALD: Atomic Layer Deposition; ARPANSA: Australian Radiation and Protection Nuclear Safety Agency
\end{abstract}

\section{Introduction}

From thousands years ago, clothes were fundamental in the protection of persons against the adverse effects of the environment (cold and hot weathers, rain, snow, wind). Only in the last decades it has been emphasized the significance of clothes against solar adverse effects, like sun burning and many other diseases, been skin cancer the most important one [1]. Recently, a factor has been introduced in order to characterize the protection a cloth gives to the person that uses it outdoor. It is called Ultraviolet (UV) protection factor (most commonly known as $U P F_{X}$ ) for a given fabric $\mathrm{X}$ and it gives the possibility to quantify the skin shielding to this harmful radiation. It was first introduced in Australia [2] and then generalized all over the world, through the CIE (Commission Internationale d'Eclairage or International Commission on Illumination) report [3,4].

Its inverse value (multiplied by 100) corresponds to the percentage transmittance of solar UV radiation,

$$
T_{U V, X}=100 / U P F_{X} \%
$$

Consequently, it cannot be less than 1. For example, if a fabric $\mathrm{X}$ has an $U P F_{X}=50$ (Table 1), it means that only $2 \%$ of the incident radiation will arrive on the skin, but if it has a value UPF
$=5$, it will permits the incidence on the skin of $20 \%$ of the solar UV radiation. The percentage solar UV protection is:

$$
P_{U V, X}=\left(100-T_{U V, X}\right) \%
$$

Table 1: UV protection factor, protection (in percentage) and protection category for fabrics, employed by the Australian Radiation Protection and Nuclear Safety Agency.

\begin{tabular}{|c|c|c|}
\hline UPF value & $\begin{array}{c}\text { Protection (in } \\
\text { Percentage) }\end{array}$ & Protection Category \\
\hline $1-14$ & $0-92.9 \%$ & Not good \\
\hline $15-24$ & $93.3-95.9 \%$ & Good \\
\hline $25-39$ & $96-97.4 \%$ & Very good \\
\hline $40-50+$ & $97.5-98+\%$ & Excellent \\
\hline
\end{tabular}

So, in the former case the protection is very high, $98 \%$ but in the latter case, only $80 \%$.

A qualification scheme has been introduced (Table 1), in order to present in a more simple way, the protection against UV solar radiation. The qualification values varies between those lowers or equal to 14 that are considered "Not good" and those equal or higher than 40 , that are "Excellent". It must be noted 
that the $50+$ qualification corresponds to all UPF values higher than 50 .

Similarly to UPF, a Solar Protection Factor $\left(\mathrm{SPF}_{\mathrm{Y}}\right)$ was previously introduced for sunscreens of type Y. In this last case, the SPF is defined as the factor that needs to multiply the maximum exposure time of a given skin phototype (ranging from I to VI following the Fitzpatrick classification [1]) exposed to the Sun, to determine the time interval before having the possibility to develop sunburn [1]. For example, as recommended by the American Academy of Dermatology, a person with Caucasian skin phototype needs to use at least a sunscreen with SPF $=30$ and can stay under intense UV solar UV radiation a maximum of 15 minutes (time interval without applied sunscreen) multiplied by 30 , or 450 minutes. However, due to transpiration, possible access to water in a piscine, sea, etc, dermatologists recommend to repeat the sunscreen application about each 2 hours.

According Gloster \& Neal [5], skin cancer is less common in darkly pigmented persons than in Caucasians because the darkly skin has a Sun Protection Factor (SPF) of up to 13.4 in blacks. However, the skin cancer in darkly pigmented persons is often associated with increased morbidity and mortality.

We like to point out that the clothes normally do not cover all the body; consequently, these recommendations need to be taken into account in combination with clothes having a high UPF.

\section{Fabric properties and materials}

Different types of fibers are employed in the production of fabrics. For example, natural fibers are made of cotton and wool and artificial fibers are mainly of polyester, nylon, Lycra, acrylic and rayon. They have quite different behaviors against solar UV radiation. One of the first characteristics to be taking into consideration is the amount of fiber/yarn per unit of surface area who determines its porosity. The lowest this quantity, the lowest the UPF. This fact can be easily confirmed observing a fabric with a light source behind (better not the Sun, since the fabric protection could be not enough if it is very low). If the visible light traverses the fabric and the source can be seen rather well, normally its UPF is quite small and consequently with low protection. On the contrary, if the light is almost not seen, the protection is quite high. It can be easily understood that bigger holes in the fabric between the fiber/yarn, permit to pass more solar radiation through it.

Other properties are:

a. The color, with darker colors absorbing more solar UV radiation than clear colors. For a given color, brilliant (reflective) fabrics, like rayon, are better than mate ones, like linen. However, a darker color absorbs efficiently solar radiation in the infrared (thermal) range, increasing the risk of heatstroke disease. Consequently, is better to use outside clothing made with a clear color fabric, but with the highest possible UPF value. Srinivan \& Gatewood [4] demonstrated that colors influence significantly the UPF value in cotton (=4.1). They obtained significant increases in the UPF value when dyes of different colors were applied (in a $0.5 \%$ concentration of weight): 20 for Yellow 28 dye, 21 for Violet 29 dye, 22 for Blue 1 and Green 26 dyes, 30 for Black 38 dye and 39 for Red 28 dye;

b. The elasticity, since if the fabric is elongated the porosity increases;

c. The density (and depth), since tight construction (and thicker fabrics) reduce the amount of UV radiation that can traverse through the fabric and

d. The water content, more quantity tends to reduce the UPF.

Besides dyes, chemicals can be added to fabrics to improve their UPF. In what follows we will analyze some treatments of this kind:

- $\quad$ Xiao et al [6] applied an Atomic Layer Deposition (ALD) [7] as a coating on a fabric, depositing $\mathrm{TiO}_{2}, \mathrm{Al}_{2} \mathrm{O}_{3}$, and $\mathrm{TiO}_{2} /$ $\mathrm{Al}_{2} \mathrm{O}_{3}$ nano-layers onto dyed polyamide/aramid blend fabric surface. This fabric showed an excellent UV resistance, suggesting that ALD technology can be used effectively to improve dyed fabrics properties.

- Gies [2] determined through laboratory tests done in the Australian Radiation and Protection Nuclear Safety Agency (ARPANSA) that Lycra fabrics normally have UPF values of 50 or $50+$, higher than nylon and polyester.

- Chakraborty et al [8] investigated the addition to cotton fabrics, of two conventional absorbers: benzophenone (that absorbs mainly in the UVB, 280-320nm wavelength range) and 2.4 dihydroxybenzophenone (mainly in the UVA, 320$400 \mathrm{~nm}$ range) and two new absorbers: avobenzone alone and avobenzone in combination with octocrylene. They obtained the (significant) result that the new absorbers increase by a factor up to 200 the UPF with respect to the conventional ones.

- $\quad$ Pakdel et al [9] analyzed the significant enhancement due to antimicrobial coating on cotton fabrics; employing metalized Titanium dioxide $\left(\mathrm{TiO}_{2}\right)$ with noble metals, Silver (Ag) and Gold $(\mathrm{Au})$ and silica. They determined a positive impact on UV protection in the case of the use of metals in the synthesis process, but a negative one in the case of silica.

\section{Results}

Employing the high quality (double monochromator with auto calibration) Optronic 756 spectroradiometer of the Institute of Physics Rosario, we first determined in Rosario, Argentina the incident spectral solar irradiance in the UV $(280-400 \mathrm{~nm})$ range. This irradiance, $I_{i n c, \text { solar }}(\lambda)$, corresponds to the solar radiation incident on a unit surface and at a unit time, for a given wavelength interval centered around $\lambda$ and having units 
of Joules $/\left(\mathrm{m}^{2}\right.$ second $\left.\mu \mathrm{m}\right)$ or Watt $/\left(\mathrm{m}^{2} \mu \mathrm{m}\right)$. Then we interposed the fabric $X$ to be analyzed and made a new measurement, that we call $I_{\text {trans }, X}(\lambda)$, the transmitted spectral solar irradiance. The ratio:

$$
T_{\text {solar }, X}(\lambda)=\frac{I_{\text {trans, solar }, X}(\lambda)}{I_{\text {inc, solar }}(\lambda)}
$$

where $T_{\text {solar }, X}(\lambda)$ is the spectral solar transmittance of fabric X.

In Figure 1 we represent $I_{\text {inc,solar }}(\lambda)$ and $I_{\text {trans, solar, } X}(\lambda)$ in the (280-400nm) UV range by continuous lines, measured in January 2012. Measurements were acquired in three different moments of the day, near noon and near the maximum of the
(Southern Hemisphere) summer, in order to avoid significant changes in the intensity of solar spectral radiation (Figure 1).

Since the measurements were made outside and consequently depend on the sky conditions (absence of clouds, no modification of the atmospheric components, no arrival of contaminant clouds of particulate matter, etc.), we verify if $I_{\text {inc,solar }}(\lambda)$ did not changed more than $5 \%$ in all the wavelength range, doing a new measurement after obtaining the transmitted spectral solar irradiance data. This condition was fulfilled, as can be seen in Figure 1 by the almost superposition of the solar radiation measured points to the continuous curve, the last one representing the incident spectral solar irradiance.

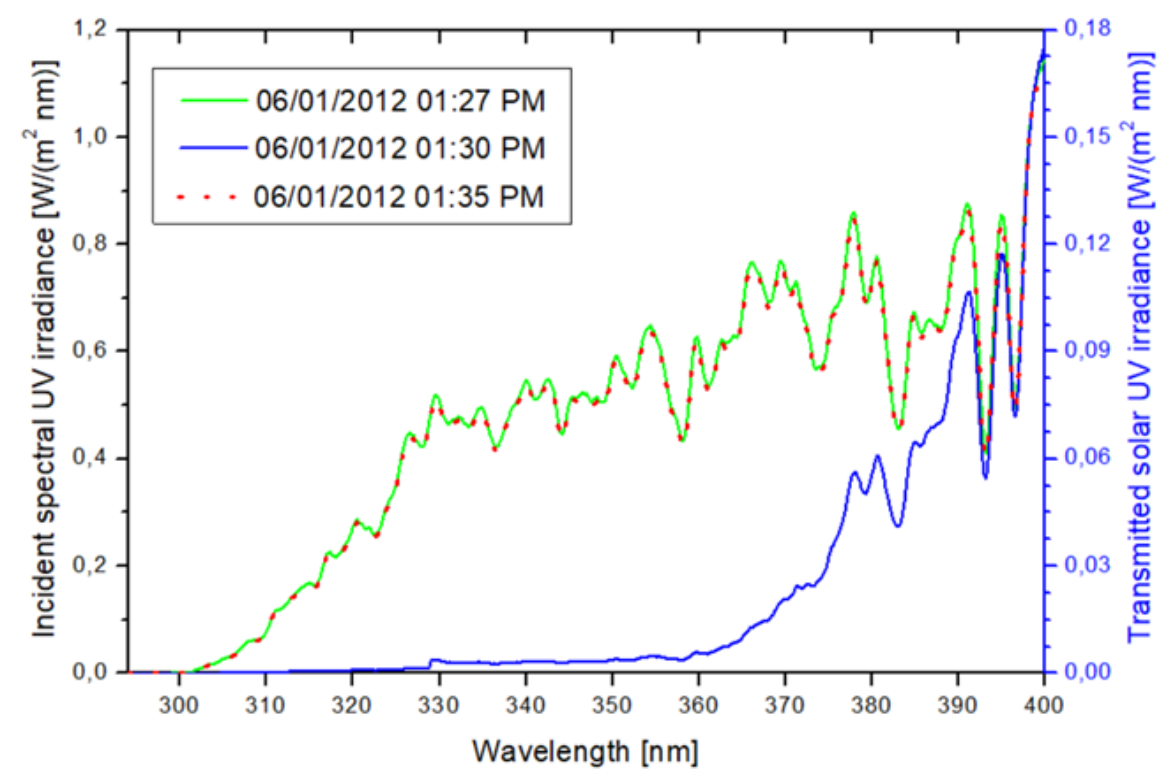

Figure 1: Spectral solar irradiance in the UV range obtained with the high quality (double monocromator with auto calibration) Optronic 756 spectroradiometer of the Institute of Physics Rosario, the day 6 January 2012, in Rosario, Argentina near local noon (=Universal time -3 hours).

Integrating (summing over all the wavelengths) each spectral irradiance, we determined the so called: incident UV irradiance $\left(I_{i n c, U V}\right)$ and transmitted solar UV irradiance $\left(I_{\text {trans }, U V, X}\right)$. Consequently, we can obtain the solar UV transmittance $T_{U V, X}^{*}=I_{\text {trans }, U V, X} / I_{i n c, U V}$. In Table 2, we present results for Lycra fabric of three different colors, with the following composition: Polyamide $85 \%$ and Elastane $15 \%$. It can be seen that the red, yellow and blue colors have quite large UV protection factors, as expected, since the dyes of the fabric absorb a large fraction (more than 98\%) of UV radiation.

Table 2: Measurement and calculation of the UV transmittance and protection due to different colors of Lycra fabric exposed to solar radiation, done with a doble monochromator Optronic 756 spectroradiometer of the Institute of Physics Rosario (CONICET - National University of Rosario), at Rosario, Argentina.

\begin{tabular}{|c|c|c|c|}
\hline Color of Lycra fabric & $T_{U V, X}^{*}$ & $\begin{array}{c}\text { Solar protection } \\
\mathbf{P}_{U V, X}=\mathbf{1 0 0}\left(\mathbf{1}-T_{U V, X}^{*}\right)(\%)\end{array}$ & $\mathbf{U P F}_{\text {solar }, X}$ \\
\hline Red & 0.018 & $98.20 \%$ & 56 \\
\hline Yellow & 0.00435 & $99.60 \%$ & 230 \\
\hline Blue & 0.00435 & $99.60 \%$ & 230 \\
\hline
\end{tabular}




\section{Current Trends in Fashion Technology \& Textile Engineering}

We like to point out that the solar UV transmittance ( $T^{*}{ }_{U V, X}$ ) values given in Table 2 were obtained in actual conditions of exposure to solar radiation, but the standardized $U P F_{X}$ is obtained in laboratory, with an artificial UV source. So, the corresponding values can differ one from the others. For comparison purposes, we like to point out that Davis et al [10] analyzed the clothing protection of different types of fabrics, and found the highest values for wool (with structure of Twill woven) of 139 and acrylic (with structure of Jersey knit) of 104.

\section{Conclusion}

From the present work, we can derive the following conclusions:

a. All fabrics that are designed to be used outside, for different activities (work, recreation, etc) need to have the indication of its UPF, and if possible, the UPF values must be 50 or larger $(50+)$, in order to have a convenient skin protection that normally do not degrades along the hours of the day as is the case of sunscreens, that need to be replaced about each two hours, as recommended by the American Academy of Dermatology. b. Babies with ages lower than a year must be putted outside solar radiation (as indicated by the Academy previously cited) and kids need to be protected with clothes that have UPF values equal or larger than 50. In particular, authors of the present work verify, through interviews with mothers in a period of 8 years (2010-2017), that in Rosario, Argentina, babies (Figure 2) and kids that used this type of clothes, do not reported solar burn or other complications of their fragile skins. Note the small Sun shadow projected by the baby in this image, demonstrating a high solar irradiance incident on the place. This is due to the fact that solar radiation needs to traverse a lower atmospheric depth near noon, producing a lower attenuation with respect to the rest of the day. The protection needs to be very efficient, since around noon in the Spring-Summer period, the Solar UV Index (internationally used for qualifying the importance of solar UV radiation incident on a given site, see for example the UNEP report on Environmental Effects of Ozone Depletion and its Interaction with Climate Change [11]) in Rosario city and nearby regions, is usually in the extreme range (values equal or higher than 11).
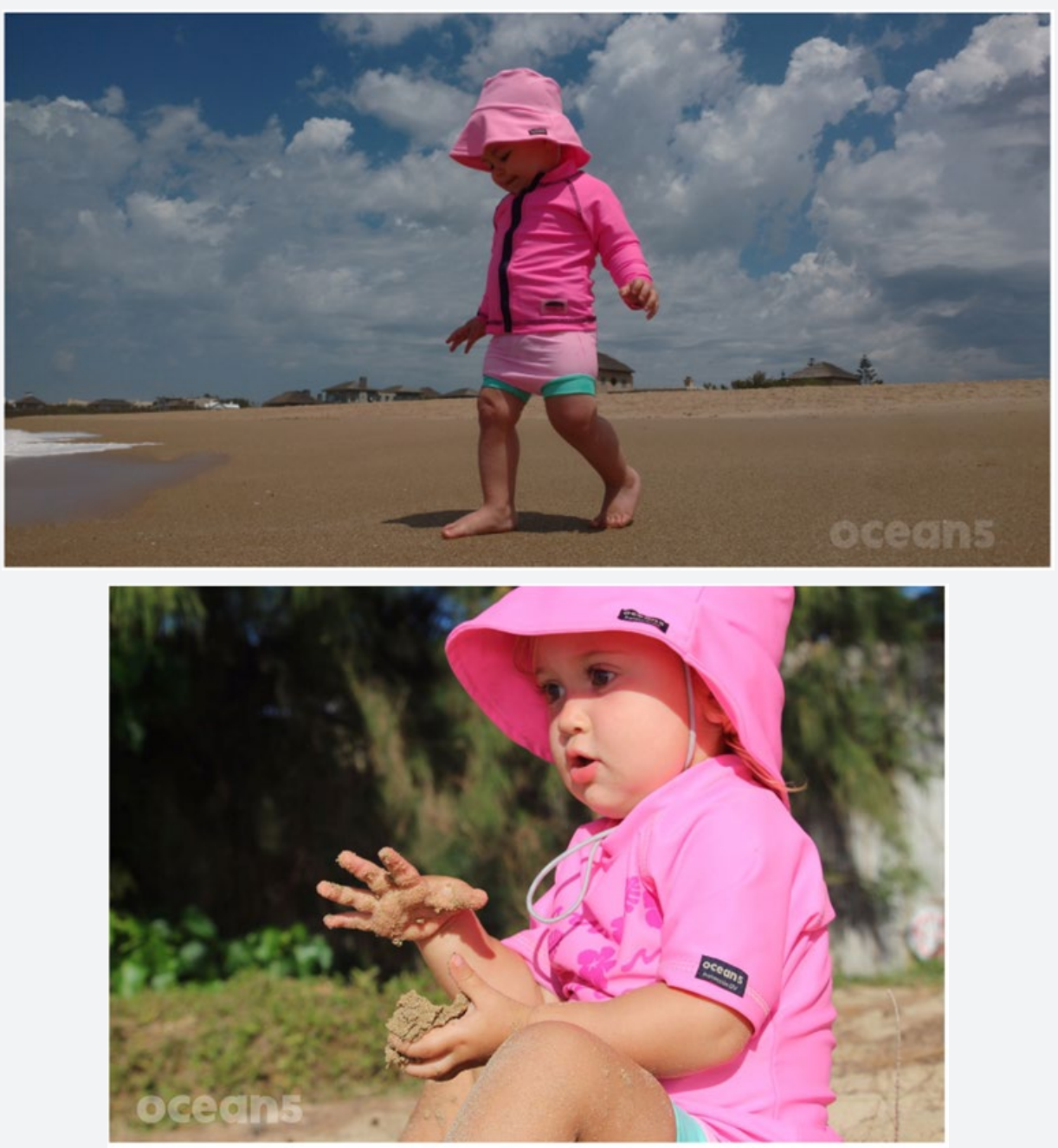

Figure 2: Babies with clothes and hat having an UPF value $50+$. Source of the image: Ocean 5. 
c. National, regional or city authorities need to incorporate legislation in this sense.

d. Besides the improvement in the materials and design of clothes resistant for UV degradation, the textile industry needs to consider a new circular economy (that optimize the use of natural resource, reduce pollution and recycle), in order to contribute to the global effort to mitigate climate change [12].

\section{Acknowledgement}

The authors like to thanks the members of the Atmospheric Physics, Solar Radiation and Astroparticles Group, Institute of Physics Rosario, CONICET-National University of Rosario, Rosario, Argentina, for technical support.

\section{References}

1. Goldsmith LA, Katz SI, Gilchrest BA," Paller A, Leffell DJ, et al. (2012) Fitzpatrick's Dermatology in General Medicine. Eighth Edition, McGraw-Hill.

2. Gies P (2007) Photo protection by clothing. Photodermatology Photoimmunology Photomedicine 23(6): 264-274.

3. CIE (International Commission on Illumination) (2006) UV protection and clothing. CIE Technical Report, pp. 172.

4. Srinivasan M, Gatewood BM (2000) Relationship of dye characteristics to UV protection provided by cotton fabric. Textile Chem Colorist Am Dyestuff Reporter 32(4): 36-43.

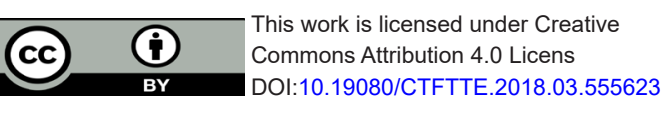

5. Gloster HM, Neal K (2006) Skin cancer in skin of color. J Am Acad Dermatol 55(5): 741-760.

6. Xiao X, Liu X, Cao G, Zhang C, Xia L, et al. (2015) Atomic layer deposition $\mathrm{TiO}_{2} / \mathrm{Al}_{2} \mathrm{O}_{3}$ nanolayer of dyed polyamide/aramid blend fabric for high intensity UV light protection. Polymer Engineering and Science 55(6): 1296-1302.

7. Fengxiang C, Xin L, Ke L, Lang J, Huiyu Y, et al. (2017) Recent progress and future challenges of functional textiles fabricated by Atomic Layer Deposition. Curr Trends Fashion Technol Textile Eng 1(3): 555-561.

8. Chakraborty JN, Sharma V, Gautam P (2014) Enhancing UV protection of cotton through application of novel UV absorbers. Journal Textile and Apparel, Technology and Management 9(1): 1-17.

9. Pakdel E, Daoud WA, Afrin T, Sun L, Wang X (2017) Enhanced antimicrobial coating on cotton and its impact on UV protection and physical characteristics. Cellulose 24(9): 4003-4015.

10. Davis S, Capjack L, Kerr N, Fedosejevs R (1997) Clothing as protection from ultraviolet radiation: which fabric is most effective? Int J Dermalol 36(5): 374-379.

11. McKenzie RL, Björn LO, Bais A, Ilyas M (2003) Changes in biologically active ultraviolet radiation reaching the Earth's surface. Photochem Photobiol Sci 2(1): 5-15.

12. Ellen MacArthur Foundation (2017) "A new textiles economy: Redesigning fashion's future" Report.

Your next submission with Juniper Publishers will reach you the below assets

- Quality Editorial service

- Swift Peer Review

- Reprints availability

- E-prints Service

- Manuscript Podcast for convenient understanding

- Global attainment for your research

- Manuscript accessibility in different formats

( Pdf, E-pub, Full Text, Audio)

- Unceasing customer service

Track the below URL for one-step submission https://juniperpublishers.com/online-submission.php 